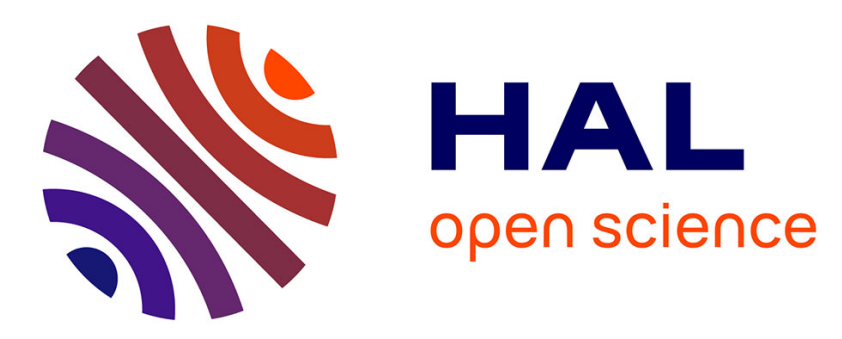

\title{
Design of a High-Speed Permanent-Magnet Machine for Electrically-Assisted Turbocharger Applications with Reduced Noise Emissions
}

Adrien Gilson, Guillaume Verez, Frédéric Dubas, Daniel Depernet, Christophe Espanet

\section{To cite this version:}

Adrien Gilson, Guillaume Verez, Frédéric Dubas, Daniel Depernet, Christophe Espanet. Design of a High-Speed Permanent-Magnet Machine for Electrically-Assisted Turbocharger Applications with Reduced Noise Emissions. International Electric Machines \& Drives Conference, May 2017, Miami, FL, United States. hal-02131017

\section{HAL Id: hal-02131017 https://hal.science/hal-02131017}

Submitted on 16 May 2019

HAL is a multi-disciplinary open access archive for the deposit and dissemination of scientific research documents, whether they are published or not. The documents may come from teaching and research institutions in France or abroad, or from public or private research centers.
L'archive ouverte pluridisciplinaire HAL, est destinée au dépôt et à la diffusion de documents scientifiques de niveau recherche, publiés ou non, émanant des établissements d'enseignement et de recherche français ou étrangers, des laboratoires publics ou privés. 


\title{
Design of a High-Speed Permanent-Magnet Machine for Electrically-Assisted Turbocharger Applications with Reduced Noise Emissions
}

\author{
Adrien Gilson ${ }^{1,2}$, Guillaume Verez ${ }^{3}$, Frederic Dubas ${ }^{2}$, Daniel Depernet ${ }^{2}$, Christophe Espanet ${ }^{1,3}$ \\ ${ }^{1}$ Advanced Research and Development dept., Moving Magnet Technologies S.A., Besancon, France \\ ${ }^{2}$ ENERGIE dept., FEMTO-ST, CNRS, Univ. Bourgogne Franche-Comte, Belfort, France \\ ${ }^{3}$ Innovation dept., Sonceboz S.A., Lausanne, Switzerland
}

\begin{abstract}
This paper addresses the issue of mitigating the noise emission of high-speed permanent-magnet (HSPM) machines. HSPM machines are increasingly used in a large field of applications for their power density and compactness. However, the increase of the speed tends to intensify the noise emissions where more and more applications require a quiet operation. The focus of this paper is to propose a HSPM structure to cope with this problem that is also well-suited to competitive markets where cost is an important factor. First, high-speed machine topologies are presented in the general case and a comparison between a reference PM slotted structure with tooth-coil windings and a slotless structure toroidally wound is made. Then, general considerations are given regarding the design parameters that impact the vibrational behavior with an analytical description and a three-dimensional (3-D) mechanical finite-element analysis (FEA). Finally, the noise emission and losses for both machines are compared showing that the slotless toroidal machine can be a good candidate for this field of applications.
\end{abstract}

Keywords-high-speed; noise; permanent-magnet; tooth-coil winding; toroidal

\section{INTRODUCTION}

The growing demand for compact and high power density systems leads to a general increase of the rotational speed of electrical machines. This is due to the fact that for a given power, increasing the speed means less torque to produce and consequently a smaller machine. The recent progress in power electronics with wide-bandgap devices ( $\mathrm{SiC}$ and $\mathrm{GaN}$ ) [1], bearing technology with air or magnetic bearings and high-end materials such as low loss amorphous or nanocrystalline iron core can now allow these machines to push the power / speed limit even further. However, the consequence of this trend is very often the increase of the noise emission level which has become a serious concern in various applications from electrically-assisted turbocharger (EAT) for passenger cars to continuous positive airway pressure (CPAP) ventilator for medical equipment. As a result, new topologies having better acoustic performances must be investigated to cope with this problem. In this area of cost-driven applications and among all the possible topologies, a clever trade-off between cost, performance (power density, peak torque, efficiency...) and noise emission level have to be found.
Noise reduction techniques have been extensively studied for numerous types of electrical machines. In the literature, induction machines (IM) [2], switched reluctance machines (SRM) [3] and PM synchronous machines (PMSM) [4] are probably the most considered. Different strategies have been used to mitigate the sound emission from several perspectives by acting on the source of the noise (electromagnetic or mechanical exciting forces) or the radiated sound (e.g. porous absorbers). As an example of exciting forces mitigation, reducing the cogging torque by using rotor/stator skewing or changing the slot-opening has always been a popular way to reduce noise. However, these strategies can become insufficient when dealing with very high-speed and a radical change of the high-speed machine topology turns out to be compulsory.

In this paper, the case of HSPM machines dedicated to EATs is investigated. A slotless toroidal machine is proposed and compared to an existing slotted machine in terms of noise emission and losses. In section II, the studied topologies are detailed, a general description of the noise generation is given and an analytical approach as well as a 3-D mechanical FEA is conducted to compare the two structures. Section III presents the results of the noise and loss measurements. Finally, section IV summarizes the key elements of the paper and concludes on the benefits of the HSPM toroidal machine.

\section{HIGH-SPEED MACHINES AND NOISE EMISSION}

\section{A. High-Speed Machines Design}

As presented in the introduction, IM, SRM and PMSM are often used to build high-speed machine. In this paper, the focus is made on PM machines mainly because they have higher power densities than IMs [5] and also because they are inherently quieter than SRMs. However, it is worth noticing that for HSPM running at high-speed in high-temperature environment such as EAT, rotor losses can be tremendously challenging to deal with and must be carefully taken into account to avoid overheating and demagnetization.

The design of HSPM is highly dependent on the mechanical aspects and cannot be solely determined by electromagnetic considerations. Thus, the maximum rotor diameter and length is constrained by the allowable tip speed (centrifugal forces acting on the rotating parts) and the rotor stability (bending modes). 
Another important aspect when dealing with high rotational speeds is the choice of the bearing system. Several technologies are used such as: high-speed ball bearings (steel or ceramic balls), air bearings (foil, tilt, etc.) and magnetic bearings (active, passive). Air and magnetic bearings allow higher rotational speeds than ball bearings but are more costly and complex to design. For that reason, in this paper both prototypes use highspeed ball bearings even though their acoustic behavior is not as good as non-contact bearing types.

In this article, the selected machine will be used in an EAT. The specifications may vary depending on the type of combustion engine and the customer needs. A power of $4 \mathrm{~kW} @$ $75 \mathrm{krpm}$ is given as a base specification. The reference machine that is used is a 6-slots/4-poles PM machine with tooth-coil windings as shown in Fig. 1 (a). A quieter alternative to this machine that meets the power and speed requirements must be found. The proposed design is a 2-poles slotless machine toroidally wound presented in Fig. 1 (b). The principal idea behind this design is to have a slotless stator to avoid permeance variation and to reduce the flux density in the airgap. Then, another design choice is to lower the number of poles to limit the fundamental frequency (positive impact on the rotor eddy current losses and the inverter switching losses). Finally, the machine is toroidally wound to achieve a good winding factor with short end-windings (in the axial direction). More details are given concerning the sizing method of these machines in [9].

\section{B. Noise Generation Process and Magnetic Forces}

As explained in [6], the process of noise generation starts with exciting forces acting on a system which will react by radiating sound into the human ear or instrument. Thus, there is three ways to lower the noise: eliminate or reduce the causes (exciting sources), play on the machine physical parameters (material, geometry) to modify the response of the system and finally isolate the sound (damping or noise insulating techniques). In this paper, we will be interested in the first two ways of noise mitigation. The impact of air-gap magnetic flux density fluctuation is studied for both machines using the description of the Maxwell pressure in polar coordinates $\mathbf{P}=$ $P_{r} \cdot \mathbf{u}_{\mathbf{r}}+P_{\theta} \cdot \mathbf{u}_{\boldsymbol{\theta}}$ which is given by equations (1) and (2). Since these quantities are calculated in the air-gap, the relation between $\mathbf{B}$ and $\mathbf{H}$ is $\mathbf{B}=\mu_{0} \mathbf{H}$ [7]. (a)

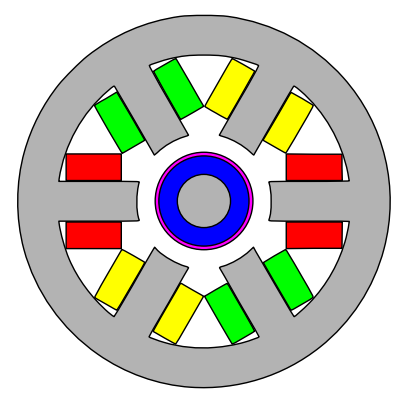

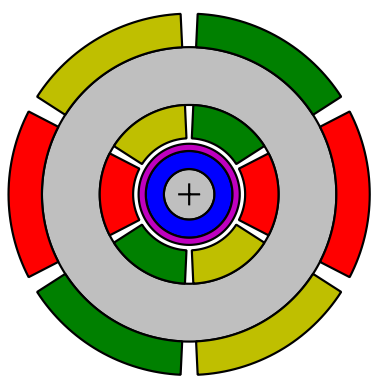

(b)
Fig. 1. High-speed machines geometry: (a) 6-slots/4-poles machine (Slotted). (b) 2-poles toroidal machine (Slotless).

$$
\begin{gathered}
P_{r}=\frac{1}{2 \mu_{0}}\left(B_{r}^{2}-B_{\theta}^{2}\right) \\
P_{\theta}=\frac{1}{\mu_{0}} B_{\theta} B_{r}
\end{gathered}
$$

where $B_{r}$ and $B_{\theta}$ are respectively the radial and tangential component of the magnetic flux density $\mathbf{B}$ and $\mu_{0}$ the vacuum permeability equal to $4 \pi \times 10^{-7} \mathrm{~T} \cdot \mathrm{m} / \mathrm{A}$.

Interactions between radial and tangential pressure, machine geometry and load conditions are a part of the various factors that significantly affect the final result. Switching from the presented teeth-wound stator to the toroidal wound stator, the following changes are expected on the magnetic force:

- Larger effective air-gap, leading to a lower force applied on the stator magnetic core.

- No slotting effect on the magnetic force and consequently less harmonics.

- Lower number of poles, changing the frequency spectrum.

In order to study the distribution of the magnetic pressure applied on the stator core bore, the FEA software Flux ${ }^{\circledR 2 D}$ is used. The magnetic field is calculated in the air-gap at $0.2 \mathrm{~mm}$ of the stator teeth (slotted) and core (slotless). The ratio between the air-gap length of the slotted machine and the slotless machine is about 1 to 3 . Then, using the Maxwell stress tensor, the radial component of the magnetic pressure is calculated according to (1). This pressure will act on the stator to produce vibrations. In Fig. 2, the instantaneous radial component of magnetic pressure is plot for both machines, on the path close to the stator core bore. Small deviations on the shape of both curves are expected when the rotor position changes. What can be concluded from Fig. 2 is that the magnetic pressure amplitude is much higher in the teeth-wound case due to stator ferromagnetic parts being closer to the rotor. The slotting effect is highly present due to teeth being rectangular without isthmus. The position of the teeth is drawn on Fig. 2 to give the reader a better understanding of the shape of the calculated pressure.

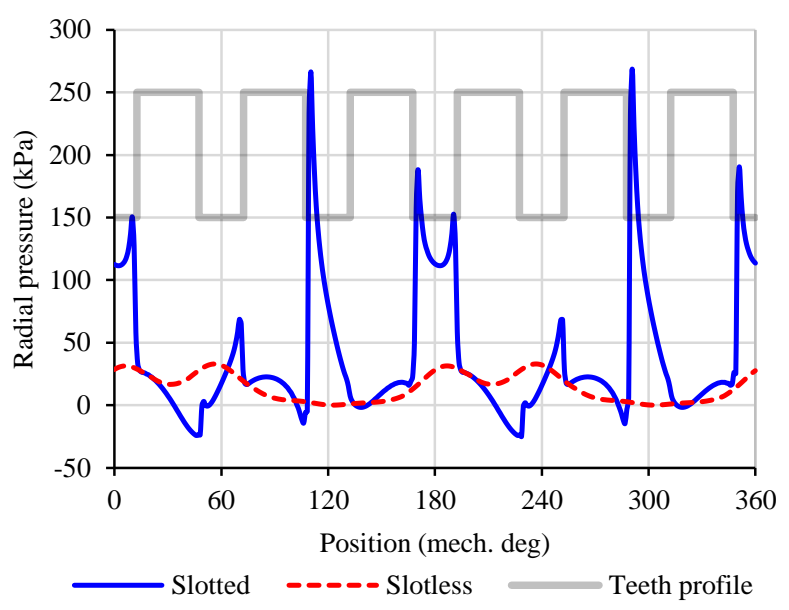

Fig. 2. On-load FEA of the radial pressure in the air-gap at $0.2 \mathrm{~mm}$ of the stator teeth for the slotted machine and $0.2 \mathrm{~mm}$ stator core for the slotless machine. 
The spatial harmonic content is shown in Fig. 3. Harmonic number 2 will induce forced and natural vibrations of circumferential mode 2 . This mode has the lowest frequency and the rotational frequency might come too close to this first mode. As a result, the amplitude of the spatial harmonic of order 2 has to be as low as possible. The toroidal machine, despite the huge differences displayed in Fig. 2, does not exhibit such a low second harmonic, it is only $33 \%$ lower. In comparison, the fourth and sixth harmonics are respectively reduced by $93 \%$ and $86 \%$.

Bi-dimensionnal fast Fourier transforms (FFTs) have been issued, to plot the effect of time harmonics (rotation) on spatial harmonics of magnetic pressure (which is dependent on time and angular position). Fig. 4 summarizes the impact of \pm 2 times the fundamental electrical frequency $f_{e}$ on the spatial harmonics. For higher time harmonic orders, the spatial harmonic orders are also higher. This is equivalent to high order circumferential modes being excited, which are not of interest due to being at high frequency, above the audible spectrum. Results shown in Fig. 4 are comparable to the ones obtained in Fig. 3 which shows that low spatial harmonic orders are almost completely excited by the $2 \times f_{e}$ time harmonic. The influence of the current loading on the teeth-wound machine is more pronounced that on the toroidal machine, especially on spatial harmonics $2(+43 \%)$ and 8 . This is less problematic on the toroidal machine since the spatial harmonic 2 is only increased by $7 \%$ by currents. However, the influence of this $2 \times f_{e}$ time harmonic is different for both machines since they have different number of rotor poles.

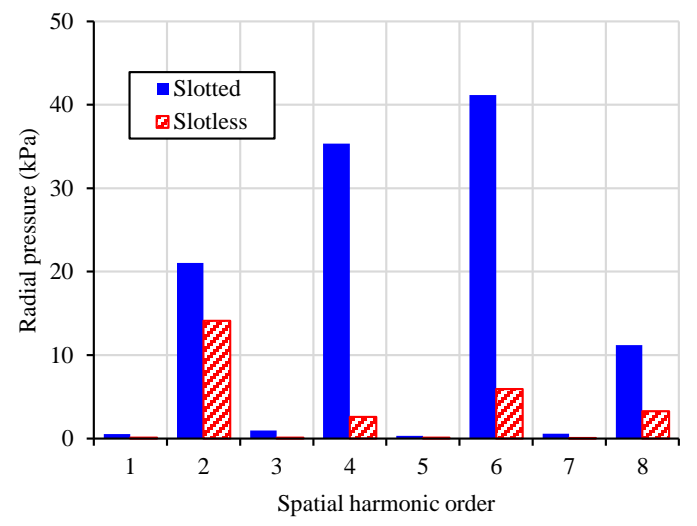

Fig. 3. Spatial harmonic content of the curves presented in Fig. 1.

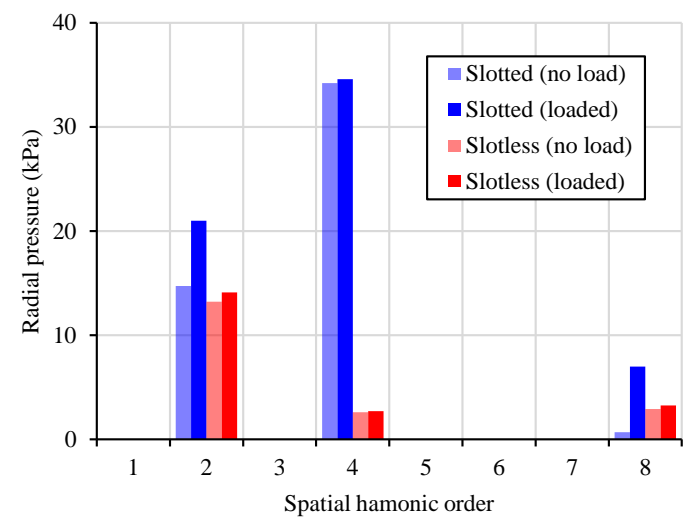

Fig. 4. Space harmonics that match $2 \times f_{e}$.

\section{Vibrationnal Behavior}

The second way to reduce the noise is to change the machine geometry to affect the structural mode and the response of the machine. Using the toroidal wound stator topology, the following changes are expected on the vibrational behavior:

- No teeth rocking, allowing for higher natural frequencies;

- Thicker stator core, allowing for higher natural frequencies;

- Toroidal winding helps distributing the mass along the stator, leading to lower displacement amplitudes.

As a first approach, using the elasticity theory of rings, without boundary conditions, the natural frequencies $f_{m}$ of the circumferential modes $m$ can be calculated according to the following equation [8]:

$$
f_{m}=\frac{m\left(m^{2}-1\right)}{\sqrt{m^{2}+1}} \alpha f_{0}
$$

where $f_{0}$ is the natural frequency of the mode number 0 defined by (4) and $\alpha$ a factor given by equation (5).

$$
f_{0}=\frac{1}{2 \pi R} \sqrt{\frac{E}{\rho}}
$$

where $R, E$ and $\rho$ are respectively the mean radius, Young's modulus and density of the stator core.

$$
\alpha=\frac{1}{2 \sqrt{3}} \frac{h}{R}
$$

where $h$ is the radial thickness of the stator core.

As compared to the teeth-wound machine, the toroidal machine's core mean radius has been reduced by $35 \%$ while the core thickness has been increased by $90 \%$. Thus, $\alpha$ and $f_{0}$ are greatly increased, and according to (3), natural frequencies, for any circumferential mode, are higher. Noise reduction can be achieved by avoiding resonance between magnetic forces and natural frequencies. A toroidal machine thus seems to be able to shift first natural frequencies to higher values, to avoid crossing them while increasing the rotational speed.

To verify this behavior, stators of the two machines are modeled using 3-D mechanical FEA. These models have been created using Salome Platform [9] and Code_Aster [10]. They have been compared to experimental tests and prove to be accurate from 0.3 to $6 \%$ on first circumferential modes [11]. As a result, models can be trusted and used as a reference for the current analysis.

As the frame used for dynamic testing of the machine is bulky and will not be used in later design stages, the change from one machine to another will be looked at without a frame. The magnetic core and windings are modeled, with free boundary conditions at each end. Natural frequencies of the toroidal machine have been calculated using FEA. Only two modes where found in the audible frequency range $(20 \mathrm{~Hz}-20 \mathrm{kHz})$, as shown in Table I. In this table, their corresponding frequency for the slotted machine are shown. Additional natural 
TABLE I. FIRST CIRCUMFERENTIAL MODES CALCULATED WITH FEA

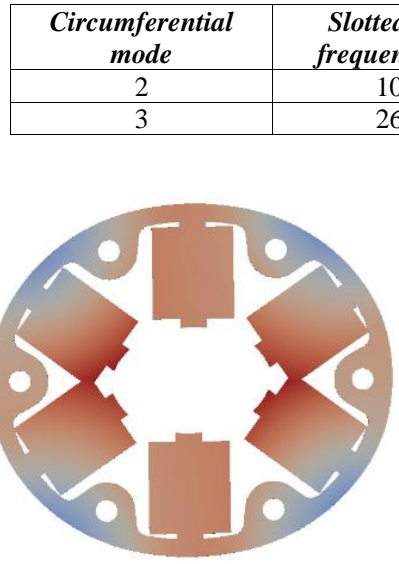

(a)

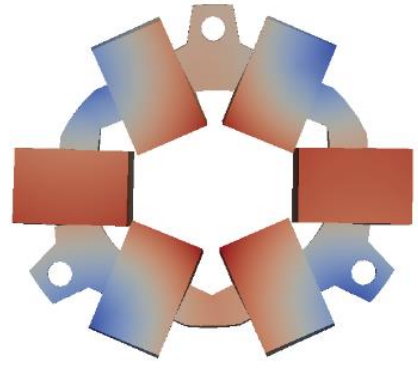

(b)
Fig. 5. Deformation of mode 2: (a) @ $1069 \mathrm{~Hz}$ for the slotted machine. (b) @ $7367 \mathrm{~Hz}$ for the slotless machine.

frequencies of the slotted machine can be found in the audible range. Modal shapes of circumferential mode 2 for both machines are shown in Fig. 5.

The study of the magnetic forces and vibrational behavior leads to the following conclusion on this part: The rotational frequencies to run at a speed $N_{r}(\mathrm{rpm}), 2 \times f_{e}=2 N_{r} / 60$ for the slotless machine and $2 \times f_{e}=4 N_{r} / 60$ for the slotted machine will be respectively called $\mathrm{H} 2$ and $\mathrm{H} 4$. Fig. 6 depicts the impact of $\mathrm{H} 2$ and $\mathrm{H} 4$ in relation with results of Fig. 4 and the modal analysis of Table I. The mode 2 is excited at a higher frequency for the toroidal machine and the amplitude of the spatial pressure harmonic 2 is lower. These two effects lead to a lower amplitude on noise, and a shift in frequency of the noise curve. The $\mathrm{H} 2$ for the toroidal machine and $\mathrm{H} 4$ for the teeth-wound machines are not following the same curve and it again goes in favor of the toroidal machine in terms of noise. The toroidal machine is thus a good candidate for noise reduction.

\section{RESULTS}

\section{A. Noise Measurements}

The HSPMs are assembled in the same aluminum frame for the comparison and Fig. 7 shows the two tests carried out on the machines. The first test presented in Fig. 7 (a) aims to verify the main motor parameters such as phase resistance, inductance, back electromotive forces and proper operating of the system at rated speed. The noise measurement test, as shown in Fig. 7 (b), takes place in a full anechoic chamber with a $13 \mathrm{~dB}(\mathrm{~A})$ background noise. HSPMs are suspended in the room and a microphone is placed at $1 \mathrm{~m}$ to record the emitted sound. Both tests are executed without any load on the machines.

Fig. 8 presents a run-up spectrogram of the 2 machines. The first thing to notice is that the slotted machine spectrogram overall noise emission is higher than the slotless machine. Then, the speed range between 70 and $80 \mathrm{krpm}$ exhibits the highest amplitude for the slotted machine as well. It is difficult using this graphs to distinguish the different modes of both structures

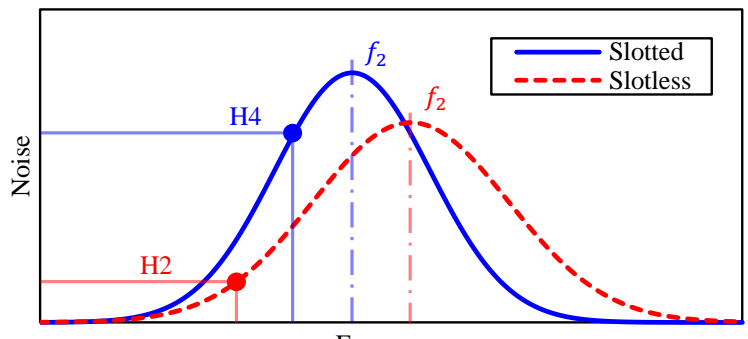

Frequency

Fig. 6. Description of the interactions between the structural mode 2 and the time harmonics $2(\mathrm{H} 2)$ and $4(\mathrm{H} 4)$.

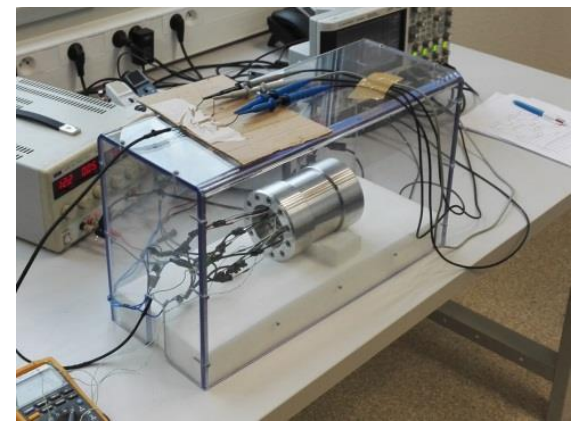

(a)

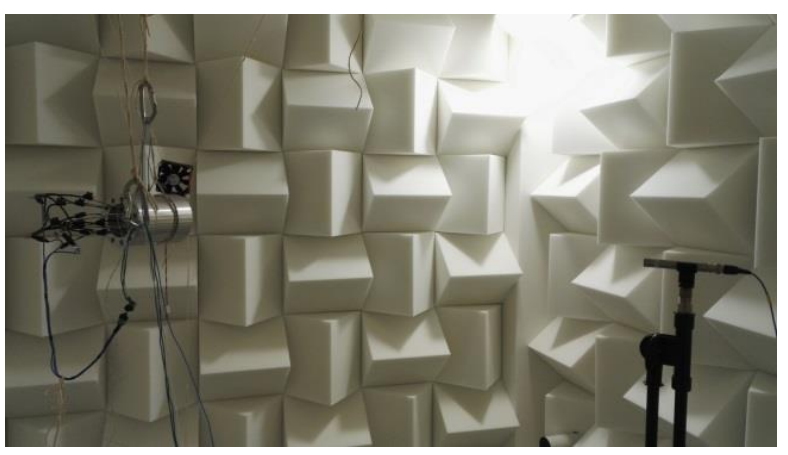

(b)

Fig. 7. Test benches: (a) Motor parameters measurement and running tests. (b) Acoustic noise measurement in the anechoic chamber.

and as explained in the previous section, the housing has a significant impact on the structural behavior of the machines.

In order to analyze the acoustic behavior at rated speed, a FFT at $75 \mathrm{krpm}$ is presented Fig. 9. As anticipated, the $\mathrm{H} 2$ is reduced for the slotless machine compared to the high amplitude of the $\mathrm{H} 4$ of the slotted machine. Other significant peaks that were not described before also appears in this graphs. The H1 for instance is due to the residual unbalance of the rotor. Some other relevant peaks can be analyzed as the rotating elements in the bearings such as balls and cage or any defects and irregularities that could appear on the bearing races.

Finally, Fig. 10 shows the generated noise at rated speed. The toroidal machine noise is reduced by $12 \mathrm{~dB}$ compared to the $70 \mathrm{~dB}$ of the slotted machine. The overall noise on the speed range is lower for the slotless machine except between 40 and $50 \mathrm{krpm}$. 


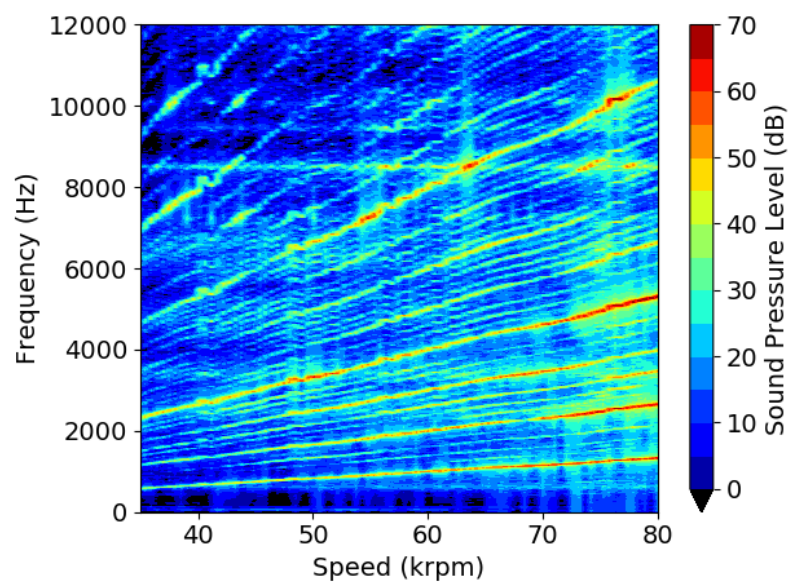

(a)

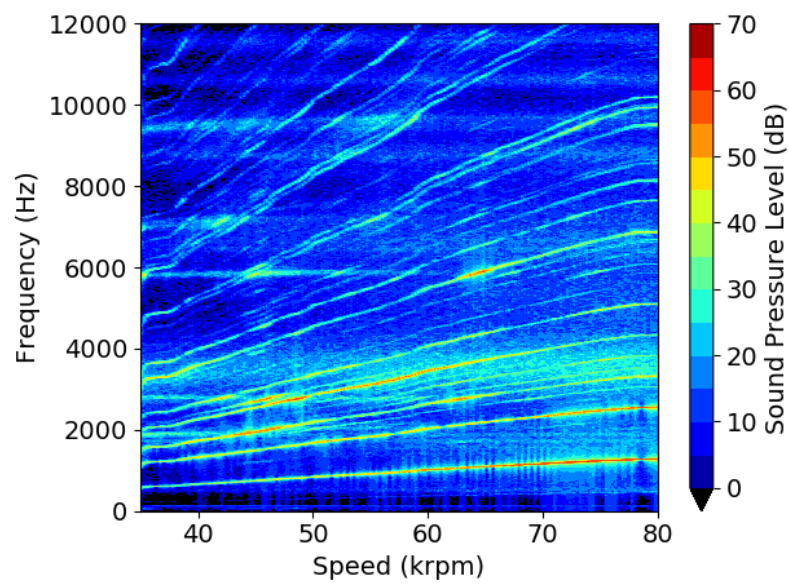

(b)

Fig. 8. Run-up spectrograms. (a) Slotted, and (b) Slotless.

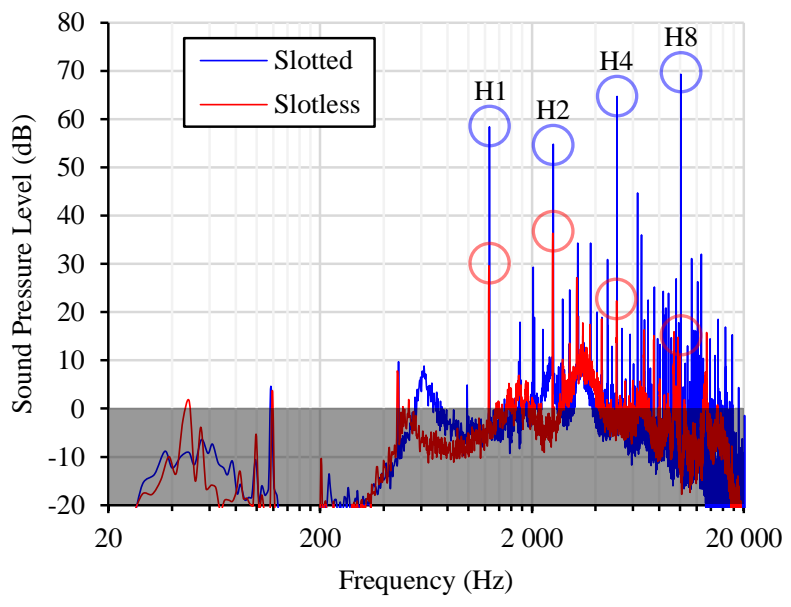

Fig. 9. FFT of the measured noise at $75 \mathrm{krpm}$.

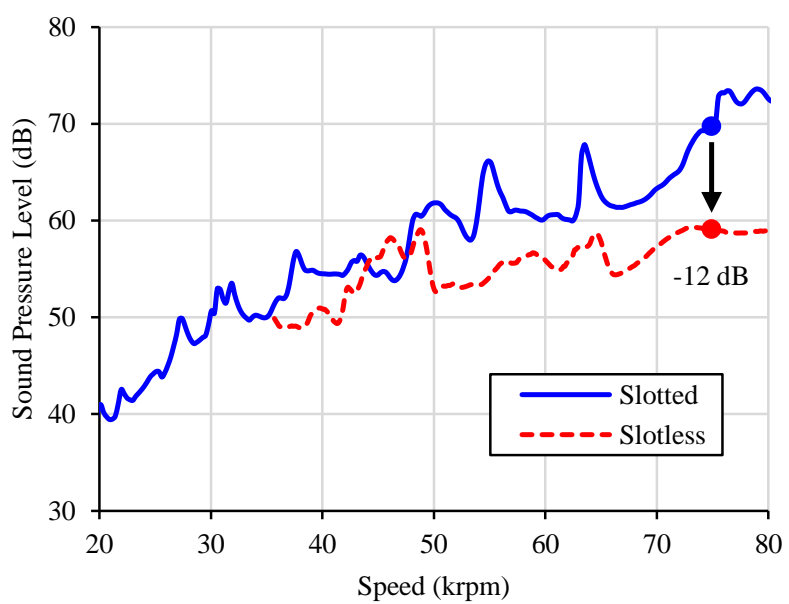

Fig. 10. Comparison of the noise emission level measured from 20 to $80 \mathrm{krpm}$ for the slotted and slotless structures.

\section{B. Loss Measurements}

The no-load losses were measured on both machines. As shown in Fig. 11, the slotless machine shows better performance when the speed increases. At rated speed, the slotless machine losses are $80 \mathrm{~W}$ which is about $38 \%$ lower than the slotted machine. These values were found by using the Newton's second law of motion and using the rotor inertia and deceleration:

$$
P_{\text {loss }}=-J \omega \frac{d \omega}{d t}
$$

where $J$ is the rotor inertia and $\omega$ the rotating speed. The accuracy of this method depends on the correctness of the value taken for the inertia. To ensure a precise measurement, another inertia is added to the rotor of which value is known accurately. This method is described with more details in [12].

Another important information concerning the design of the slotless machine is that the use of Litz wire turned out to be mandatory at that level of speed. Fig. 12 presents the loss measurements of the slotless machine with and without the use of Litz wire. Even if the wire diameter was chosen close to 2 skin depth at the fundamental frequency, the effect of the currents induced by the rotating magnet led to a tremendous amount of losses in the winding. This observation is of great importance when considering the design of slotless machines whereas the effect on slotted machines is mitigated by the presence of slots.

\section{CONCLUSION}

In this paper, a description of the possible HSM topologies and their design was detailed. Then, an overview of the noise generation mechanisms was given with a focus on the electromagnetic sources. A 2-poles HSPM toroidal machine was proposed to be compared to a reference slotted machine in terms of noise emission and an analytical approach and FEA were conducted to justify the design choices. To summarize, the main 


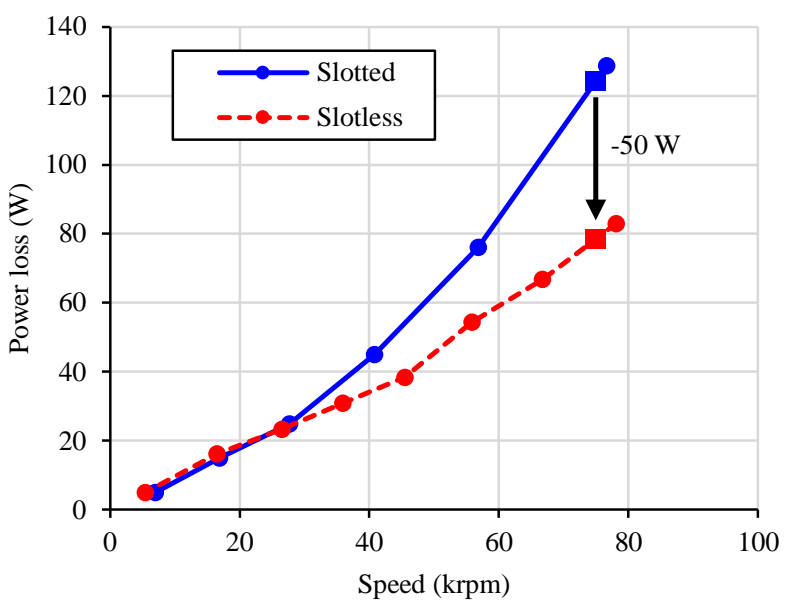

Fig. 11. Power loss measurements.

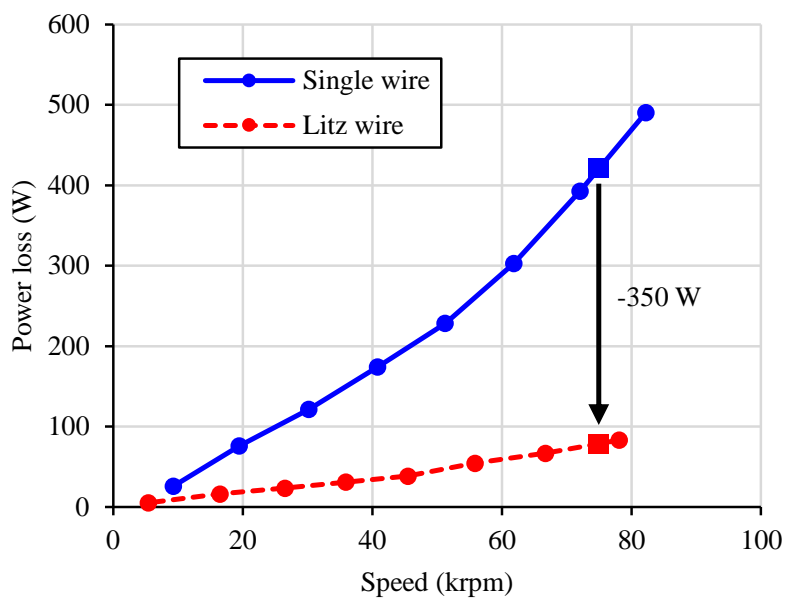

Fig. 12. Power loss measurements of the slotless machine being wound using a single wire or Litz wire.

reasons for selecting this machine topology were:

- No teeth rocking due to tangential forces;

- Thicker and smaller stator core;

- Larger effective air-gap, leading to a lower force applied on the stator magnetic core;

- No slotting effect on the magnetic force;

- Lower number of poles, changing the frequency spectrum.
The toroidal machine was measured $12 \mathrm{~dB}$ under the slotted machine noise level at the rated speed of $75 \mathrm{krpm}$ and the noload losses were $38 \%$ lower.

The future steps and important aspects that were not addressed in this paper are:

- On-load losses: The toroidal machine was proven to be quieter than the slotted machine but the on-load losses have to be compared to demonstrate that the machine is able to meet the power requirement. The use of Litz wire to mitigate the eddy current led to a lower copper filling factor than expected and thus an increase in copper losses;

- The acceleration: EAT applications are very dynamic and a measurement of the on-load acceleration of the slotless machine is required.

\section{REFERENCES}

[1] Y. Li, D. Han, N. Altintas, and B. Sarlioglu, "Design of high-speed toroidal winding surface PM machine with SiC-based inverters," in XXII International Conference on Electrical Machines (ICEM), 2016, pp. 1559-1565.

[2] S. Baldizzone, C. J. Novak, and N. C. Kar, "Experimental investigations of noise and vibration in electric machines," in IEEE Transportation Electrification Conference and Expo (ITEC), 2012, pp. 1-6.

[3] K. Kiyota, T. Kakishima, A. Chiba, and M. A. Rahman, "Cylindrical Rotor Design for Acoustic Noise and Windage Loss Reduction in Switched Reluctance Motor for HEV Applications," IEEE Transactions on Industry Applications, vol. 52, no. 1, pp. 154-162, Jan. 2016.

[4] J. L. Besnerais, "Effect of lamination asymmetries on magnetic vibrations and acoustic noise in synchronous machines," in 18th International Conference on Electrical Machines and Systems (ICEMS), 2015, pp. $1729-1733$

[5] J. F. Gieras, "Design of permanent magnet brushless motors for high speed applications," in 17th International Conference on Electrical Machines and Systems (ICEMS), 2014, pp. 1-16.

[6] P. L. Timar, A. Fazekas, J. Kiss, A. Miklos, and S. J. Yang, Noise and Vibration of Electrical Machines. Elsevier, 1989.

[7] J. R. Melcher, Continuum electromechanics. Cambridge, Mass.: MIT Press, 1981.

[8] R. Hoppe, "Vibrationen eines ringes in seiner ebene," Journal für die reine und angewandte Mathematik, vol. 73, pp. 158-170, 1871.

[9] Salome Platform, http://www.salome-platform.org/. 2017.

[10] Code_Aster, http://web-code-aster.org/. 2017.

[11] G. Verez and C. Espanet, "Natural frequencies analytical modeling of small industrial radial flux permanent magnet motors," in 18th International Conference on Electrical Machines and Systems (ICEMS), 2015, pp. 1963-1969.

[12] A. Gilson, S. Tavernier, M. Gerber, F. Dubas, D. Depernet, and C. Espanet, "Design of a Cost-Efficient High-Speed High-Efficiency PM Machine for Compressor Applications," presented at the Energy Conversion Congress and Exposition (ECCE), Montreal, Canada, 2015. 